\title{
Feeding on Lettuce and Mulberry Leaves Increases Silk Productivity and Biometrics of the Mulberry Silkworm Bombyx Mori
}

\section{Idriss $\mathbf{M}$ and Gad $\mathbf{A A}^{*}$ \\ Department of Applied Entomology and Zoology, Alexandria University, Egypt}

*Corresponding author: Abir A Gad, Department of Applied Entomology and Zoology, Faculty of Agriculture, (El-Shatby), Alexandria University, Egypt, Email: Abir_gad@yahoo.com

\section{Research Article \\ Volume 2 Issue 5}

Received Date: October 09, 2019

Published Date: October 18, 2019

DOI: $10.23880 /$ izab- 16000182

\section{Abstract}

During the present study, two different host plants (lettuce and mulberry) were used for feeding $5^{\text {th }}$ instar larvae of Bomby mori. In the case of treatment $\left(\mathrm{T}_{0}\right)$, B. mori $5^{\text {th }}$ instar larvae were daily fed on 4 meals of mulberry leaves (control treatment), while in treatment $\left(\mathrm{T}_{1}\right)$, larvae were fed on 10 meals of lettuce leaves: 4 meals at the $1^{\text {st }}$ day, 3 meals at the $2^{\text {nd }}$ day, 2 meals at the $3^{\text {rd }}$ day and a meal at the $4^{\text {th }}$ day; the rest of the fourth daily meals were mulberry leaves. ( $\left.\mathrm{T}_{2}\right)$, larvae were fed on 6 meals of lettuce leaves: 3 meals at the $1^{\text {st }}$ day, 2 meals at the $2^{\text {nd }}$ day and a meal at the $3^{\text {rd }}$ day; the rest of the fourth daily meals were mulberry leaves. $\left(\mathrm{T}_{3}\right)$ larvae were fed on 3 meals of lettuce leaves: 2 meals at the $1^{\text {st }}$ day and a meal at the $2^{\text {nd }}$ day; the rest of the fourth daily meals were mulberry leaves. $\left(\mathrm{T}_{4}\right)$, larvae were fed on a meal of lettuce leaves at the $1^{\text {st }}$ day: the rest of the fourth daily meals were mulberry leaves. $\left(\mathrm{T}_{5}\right)$, larvae were daily fed on a meal of lettuce leaves and 3 meals of mulberry leaves. $\left(\mathrm{T}_{6}\right)$, larvae were daily fed on 4 meals of lettuce leaves. The present results revealed that $\mathrm{T}_{5}$ significantly increased the larval weight as compared with the other treatments $\left(\mathrm{T}_{0}, \mathrm{~T}_{1}, \mathrm{~T}_{2}, \mathrm{~T}_{3}\right.$, and $\left.\mathrm{T}_{4}\right)$. While $\mathrm{T}_{2}$ significantly increased the mean of pupal, cocoon, cocoon shell and silk gland weights by about $46.2 \%, 44.6 \%$, $37.6 \%$ and $55.7 \%$ respectively as compared with the $\mathrm{T}_{0}$. The effect of feeding of $B$. mori $5^{\text {th }}$ instar larvae on lettuce leaves on total and different haemocyte counts of B.mori last larval instar was also determined.

Keywords: Silkworm; Lactuca Sativa; Mulberry Leaves; Economic Parameters 


\section{International Journal of Zoology and Animal Biology}

\section{Introduction}

Silkworm, Bombyx mori L., as a monophagous insect get all required nutrients for its growth and development from mulberry leaves. In Egypt the climatical conditions and the efficiency of mulberry leaves allow only the rearing of monovoltine races of Bombyx mori L. The most important objective in the sericulture problems is to find out applicable methods to increase silk production. Thus, we have to continue our search to achieve an increase in the productivity of the silk yield of the mulberry silkworm. Nutrition plays a major role in sericulture field. It improves the silkworm growth, development, and feed consumption of silkworm which improving the silk yield.

Paul, et al. [1] noticed that mulberry leaf quality has direct effect on larval food consumption and growth.

Mulberry leaves varieties have significantly effect on shell and pupal weight. Perhaps, this could be because of more repeated contact with food, the time for conversion of assailants into body tissue is reduced such that more of the digested food is stored to be silk fibers. This is supported by the explanation of silk production in the silkworm by Narasimhana, et al. [2].

Adeduntan, et al. [3] found that feeding silkworm on varieties of mulberry leaves affected significantly on mortality of larva and cocooning, while its was not significant effect on good cocoon, flimsy cocoon, stained cocoons, cocoon shell weight and pupa weight, oviposition, egg fertility and hatchability.

Nasreen, et al. [4] fed the third instar larvae of B. mori on leaves of peepal (Ficus religiosa) and the larvae produced good cocoons as compared to those fed on mulberry.

The effect of some mulberry varieties on silk worms growth and silk production were studied in India [5].

Muthunagai, et al. [6] observed that feeding the $3^{\text {rd }}$ larval instar of B. mori with Ricinus communis leaves shown wriggling movement and moved towards the corners of the tray. Also, Sign of annoyance and weakness was noticed.

Lettuce (Lactuca sativa) was first cultivated in ancient Egypt for the production of oil from its seeds. It was considered an important treatment for numerous diseases. Its nutritional contents were reported to contain high quantities of vitamins, riboflavin, antioxidants and minerals $[7,8]$.

Most of the research was concerned on rearing mulberry leaves. A few number of noticeable work was done on alternative hosts that could be used to get better silk quality and quantity. The main point of the present study was to find out new host plants for silkworm (Bombyx mori L.) larvae to increase the silk production.

In the present work we chose lettuce leaves because it is abundant in Egypt and cheap in price.

\section{Materials and Methods}

\section{Insect Material}

The PMXCSR2 hybrid of the mulberry silkworm Bombyx mori (Lepidoptera: Bombycidae), was procured from Sericulture and Agriculture Experiment Station, Vratza, Bulgaria. The silkworm larvae were reared according to Krishnaswami, et al.

\section{Experimental Design}

The present study was carried out on the $5^{\text {th }}$ instar larvae of the mulberry silkworm Bombyx mori (Lepidoptera: Bombycidae). It was designed to examine the effect of feeding regime of B. mori $5^{\text {th }}$ instar larvae on lettuce and mulberry leaves. Freshly ecdysed B. mori $5^{\text {th }}$ instar larvae were used for all experimental treatments. The experimented larvae were separated into seven groups. Each group contained three replicates, each replicate consists of 50 larvae. Experimental treatments were:

\section{Treatment-0 $\left(\mathrm{T}_{\mathbf{0}}\right)$ :}

Daily, larvae were fed on 4 meals of mulberry leaves.

\section{Treatment-1 $\left(\mathrm{T}_{\mathbf{1}}\right)$ :}

Day 1, larvae were fed on 4 meals of lettuce leaves.

Day 2, larvae were fed on 3 meals of lettuce leaves and 1 meal of mulberry leaves.

Day 3, larvae were fed on 2 meals of lettuce leaves and 2 meals of mulberry leaves.

Day 4, larvae were fed on 1 meal of lettuce leaves and 3 meals of mulberry leaves.

Day 5 to the end of last larval instar, larvae were fed on 4 meals of mulberry leaves.

\section{Treatment-2 ( $\left.\mathbf{T}_{2}\right)$ :}

Day 1, larvae were fed on 3 meals of lettuce leaves and 1 meal of mulberry leaves.

Day 2, larvae were fed on 2 meals of lettuce leaves and 2 meals of mulberry leaves. 


\section{International Journal of Zoology and Animal Biology}

Day 3, larvae were fed on 1 meal of lettuce leaves and 3 meals of mulberry leaves.

Day 4 to the end of last larval instar, larvae were fed on 4 meals of mulberry leaves.

\section{Treatment-3 ( $\left.\mathbf{T}_{3}\right)$ :}

Day 1, larvae were fed on 2 meals of lettuce leaves and 2 meals of mulberry leaves.

Day 2, larvae were fed on 1 meal of lettuce leaves and 3 meals of mulberry leaves.

Day 3, to the end of last larval instar, larvae were fed on 4 meals of mulberry leaves.

\section{Treatment-4 ( $\left.\mathrm{T}_{4}\right)$ :}

Day 1, larvae were fed on 1 meal of lettuce leaves and 3 meals of mulberry leaves.

Day 2, to the end of last larval instar, larvae were fed on 4 meals of mulberry leaves.

\section{Treatment-5 $\left(\mathrm{T}_{5}\right)$ :}

Daily, larvae were fed on 1 meal of lettuce leaves and 3 meals of mulberry leaves.

\section{Treatment-6 $\left(\mathrm{T}_{\mathbf{6}}\right)$ :}

Daily, larvae were fed on 4 meals of lettuce leaves.

Mortality was recorded daily for all the experimental groups. Biometrics such as larval weight, larval duration and cocoon parameters (cocoon weight, shell weight and pupal weight) were recorded.

\section{Haemolymph Preparation}

The haemolymph samples were taken from $5^{\text {th }}$ instar larvae at mature larval stage. The total haemocyte count was calculated according to Jones, et al. [9]. To calculate the different haemocyte count, 100 cells were identified to their typical haemocyte type after staining a smear of haemolymph with Wright stain [10].

\section{Statistical Analysis}

All results were expressed as mean \pm standard errors. Statistical analyses were performed with one-way analysis of variance followed by unpaired two-tailed Student's $t$-test. A $p$-value $<0.05$ was considered to be significant.

\section{Results}

\section{Effect on Some Biological Parameters}

The Analysis of Variance has indicated high significant differences (at $p=0.05$ ) between the treatment values in respect of larval weight, pupal weight, cocoon weight, shell weight and, silk gland weight are shown in (Figure 1). B. mori larvae which fed on lettuce and mulberry leaves significantly increased the larval weight, cocoon weight, pupal weight, shell weight and shell ratio.

Feeding silkworms with lettuce leaves larvae $\left(\mathrm{T}_{5}\right)$ gave highest larval weight about $3.623 \pm 0.01 \mathrm{~g}$ followed by $\left(\mathrm{T}_{6}\right)$ (larvae fed with lettuce leaves only) about $3.559 \pm 0.03 \mathrm{~g}$.

The average of cocoon weights were found to be highest at $\mathrm{T}_{2}(1.362 \pm 0.03 \mathrm{~g})$ followed by $\mathrm{T}_{3}(1.276 \pm 0.03 \mathrm{~g})$ then $\mathrm{T}_{1}(1.269 \pm 0.06 \mathrm{~g})$. No significant differences were observed between $\mathrm{T}_{4}(1.193 \pm 0.01 \mathrm{~g})$ and $\mathrm{T}_{5}(1.135 \pm 0.01$ g) while the mean weight $\mathrm{T}_{0}$ was $0.942 \pm 0.02$ and no cocoons were obtained at $\mathrm{T}_{6}$.

As shown in Figure1 Significant differences in the mean weights of $B$. mori pupae were recorded. The mean pupal weights were $0.764 \pm 0.02,1.040 \pm 0.01,1.117 \pm 0.05$, $1.044 \pm 0.04,0.973 \pm 0.02$ and $0.936 \pm 0.01 \mathrm{~g}$ for $\mathrm{T}_{0}, \mathrm{~T}_{1}, \mathrm{~T}_{2}, \mathrm{~T}_{3}$, $\mathrm{T}_{4}$ and $\mathrm{T}_{5}$ respectively. No pupae were obtained at $\mathrm{T}_{6}$. The highest means of pupal weights were observed at $\mathrm{T}_{2}$ (by about $46.2 \%$ more than $\mathrm{T}_{0}$ ) followed by $\mathrm{T}_{3}(36.6 \%)$ then $\mathrm{T}_{1}(36.1 \%)$.

Furthermore, the average of cocoon weights were found to be highest at $\mathrm{T}_{2}(1.362 \pm 0.03 \mathrm{~g})$ followed by $\mathrm{T}_{3}$ $(1.276 \pm 0.03 \mathrm{~g})$ then $\mathrm{T}_{1}(1.269 \pm 0.06 \mathrm{~g})$. No significant differences were observed between $\mathrm{T}_{4}(1.193 \pm 0.01 \mathrm{~g})$ and $\mathrm{T}_{5}(1.135 \pm 0.01 \mathrm{~g})$ while the mean weight $\mathrm{T}_{0}$ was $0.942 \pm 0.02$ and no cocoons were obtained at $\mathrm{T}_{6}$.

The average of silk gland weights were found to be highest at $\mathrm{T}_{2}(1.247 \pm 0.03 \mathrm{~g})$ followed by $\mathrm{T}_{3}(1.204 \pm 0.03 \mathrm{~g})$ then $\mathrm{T}_{4}(1.186 \pm 0.01 \mathrm{~g})$. No significant differences were observed between $\mathrm{T}_{1}(1.105 \pm 0.02 \mathrm{~g})$ and $\mathrm{T}_{5}(1.053 \pm 0.05$ g). Also, there were no significant differences between $\mathrm{T}_{0}$ $(0.801 \pm 0.04 \mathrm{~g})$ and $\mathrm{T}_{6}(0.773 \pm 0.01 \mathrm{~g})$.

$\mathrm{T}_{2}$ treatment significantly increased the average cocoon shell weights when compared with control $\mathrm{T}_{0}$. The mean shell weights were $0.178 \pm 0.01,0.229 \pm 0.01$, $0.245 \pm 0.01,0.232 \pm 0.03,0.220 \pm 0.02$ and $0.199 \pm 0.02 \mathrm{~g}$ for $\mathrm{T}_{0}, \mathrm{~T}_{1}, \mathrm{~T}_{2}, \mathrm{~T}_{3}, \mathrm{~T}_{4}$ and $\mathrm{T}_{5}$ respectively. The highest means of shell weights were observed at $\mathrm{T}_{2}$ ( by about $37.6 \%$ more than $\mathrm{T}_{0}$ ) followed by $\mathrm{T}_{3}(30.3 \%)$ then $\mathrm{T}_{1}(28.7 \%)$ and $\mathrm{T}_{4}$ $(23.6 \%)$

Fig.,(1).
Idriss $\mathrm{M}$ and Gad AA. Feeding on Lettuce and Mulberry Leaves Increases Silk Productivity and Biometrics of the Mulberry Silkworm Bombyx Mori. Int J Zoo Animal Biol 2019, 2(5): 000182. 


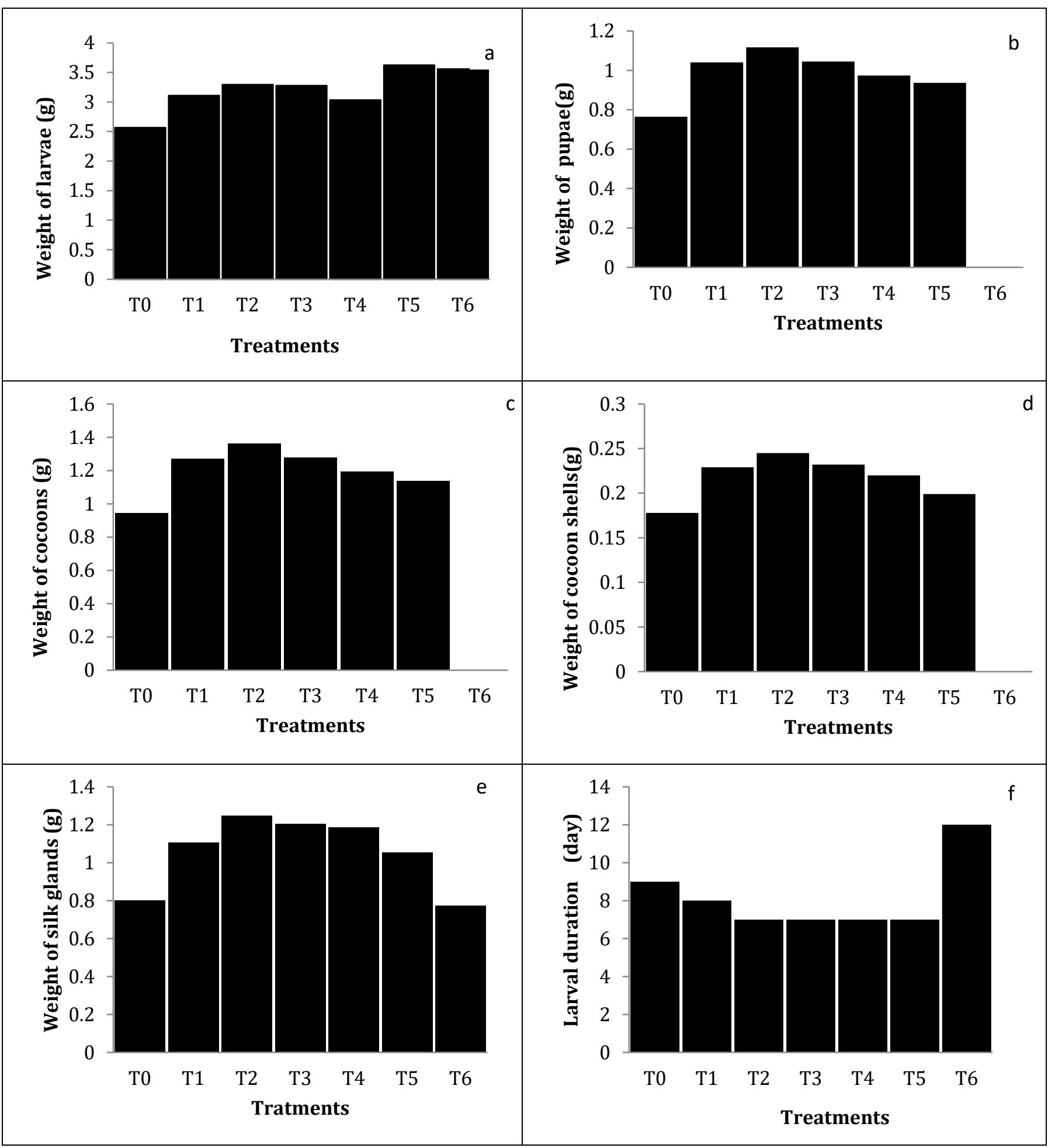

Figure 1: Effect of lettuce leaves feeding on some biological parameters.
a.Larval weight
b. Pupal weight
c. Cocoon weight
d. Cocoon shell weight
e. Silk gland weight
f. Larval duration 


\section{International Journal of Zoology and Animal Biology}

\section{Effect on Larval Duration}

Feeding on lettuce leaves only $\left(\mathrm{T}_{6}\right)$ have exerted significant increase the total larval duration (12 days). The other treatments $\mathrm{T}_{1}, \mathrm{~T}_{2}, \mathrm{~T}_{3}, \mathrm{~T}_{4}$ and $\mathrm{T}_{5}$ recorded least larval duration ( 7 days) while $\mathrm{T}_{2}$ was ( 8 days) and control was (9days) Figure 1.

\section{Hemocyte Count}

In this work the effect of nutrition on blood picture was studied, because haemocytes reflect the physiological status of larvae after feeding on lettuce leaves. Also, the toxic effect of some nutritional tested groups on haemocytes and accordingly, on the endocrine glands and hormones which affecting on the larval growth and development.
The light microscopic observations of the stained larval hemolymph revealed the presence of four morphologically distinct types of heamocytes.

Prohaemocytes (Pr), Granulocytes (Gr), Plasmatocytes $(\mathrm{Pl})$ and Oenocytoides (Oe) were monitored. All tested groups clearly affected on the total and differential haemocytes counts of $5^{\text {th }}$ instar larvae of $B$. mori.

With regard to lettuce and mulberry leaves feeding, a significant decrease in the percentage of the Pr was observed about -31.9 and $-44.4 \%$ after feeding as a group $\left(\mathrm{T}_{2}\right)$ and $\left(\mathrm{T}_{3}\right)$, respectively (Table 1$)$. A significant increase was observed in the number of granulocyte after feeding as a group $\left(\mathrm{T}_{2}\right)$ and $\left(\mathrm{T}_{3}\right)$ about 31.06 and $22.65 \%$, respectively.

\begin{tabular}{|c|c|c|c|c|c|}
\hline Treatments & THC & Pr & Gr & Pl & Oe \\
\hline Control & $29600 \mathrm{~d}$ & $4.5 \pm 0.4^{\mathrm{a}}$ & $25.6 \pm 0.9^{\mathrm{c}}$ & $23.6 \pm 1.1^{\mathrm{d}}$ & $9.1 \pm 0.6^{\mathrm{d}}$ \\
\hline T1 & $32000^{\mathrm{c}}$ & $3.7 \pm 0.3^{\mathrm{b}}$ & $27.5 \pm 1.2^{\mathrm{b}}$ & $24.3^{\mathrm{b}} .^{\mathrm{c}}$ & $13.6 \pm 1.2^{\mathrm{b}}$ \\
\hline $\mathrm{T} 2$ & $46600^{\mathrm{a}}$ & $3.0 \pm 0.3^{\mathrm{c}}$ & $35.6 \pm 1.2^{\mathrm{a}}$ & $28.5 \pm 0.6^{\mathrm{a}}$ & $15.5 \pm 0.6^{\mathrm{a}}$ \\
\hline T3 & $35250^{\mathrm{b}}$ & $2.5 \pm 0.4^{\mathrm{d}}$ & $33.1 \pm 0.7^{\mathrm{a}}$ & $27.2 \pm 1.6^{\mathrm{a}}$ & $15.2 \pm 1.6^{\mathrm{a}}$ \\
\hline T4 & $31000^{\mathrm{c}}$ & $2.2 \pm 0.8^{\mathrm{d}}$ & $32.3 \pm 1.3^{\mathrm{a}}$ & $25.5 \pm 1.2^{\mathrm{b}}$ & $14.3 \pm 1.2^{\mathrm{b}}$ \\
\hline T5 & $25750^{\mathrm{d}}$ & $1.6 \pm 0.2^{\mathrm{e}}$ & $23.6 \pm 0.7^{\mathrm{b}}$ & $22.5 \pm 1.2^{\mathrm{c}}$ & $12.5 \pm 1.2^{\mathrm{c}}$ \\
\hline T6 & $22452^{\mathrm{e}}$ & $1.2 \pm 0.5^{\mathrm{f}}$ & $21.5 \pm 0.8^{\mathrm{c}}$ & $20.7 \pm 0.8^{\mathrm{d}}$ & $11.7 \pm 0.8^{\mathrm{c}}$ \\
\hline
\end{tabular}

Table 1: The effects of feeding B. mori $5^{\text {th }}$ instar larvae on lettuce and mulberry leaves in total and different heamocyte count. Data are mean \pm SE. The statistical analyses were performed using unpaired two-tailed Student's t-test $\left({ }^{*} \mathrm{p}<0.05\right)$.

Feeding the $5^{\text {th }}$ larval instar as a group $\left(\mathrm{T}_{2}\right)$ and $\left(\mathrm{T}_{3}\right)$ increased the number of $\mathrm{Pl}$ about 20.7 and 15.25\%, respectively. Also, the number of Oe significantly increased about 70.3 and $67.03 \%$, respectively more than control.

On the other hand, the number of $\mathrm{Pr}, \mathrm{Gr}$ and $\mathrm{Pl}$ markedly decreased after larvae fed as a group $\left(\mathrm{T}_{6}\right)$ about 22.8, 16.01 and 12.2, respectively less than control. While the number of Oe significantly increased about $28.5 \%$ more than control (Table 1).

\section{Discussion}

Lettuce (Lactuca sativa) was cultivated the first time in ancient Egypt for producing oil from its seeds. Lettuce leaves contain high amount of vitamins (A,C,K,B group), riboflavin, antioxidants (beta-carotene, LuteinZeaxanthin, flavonols, minerals (calcium, magnesium, iron, iodine, zinc, copper, manganese, selenium) $[7,8]$.

Silkworm is commonly raised on leaves of different varieties of mulberry (Morus sp.) There had always been a search for alternate host plants which can raise silkworm larvae to produce better silk in quality and quantity like Morus nigr [6]. Also, tried to feed silkworm larvae on mixed feeding. He noted that mixed feeding improved the insect growth as compared to feed on leaves of a single plant species [6].

In the present study feeding on lettuce and mulberry leaves together may have a useful effect on the growth of the silkworm Bombyx mori and also increased the larval weight, pupal weight, cocoon weight, shell ratio and silk gland weight by increase feeding efficacy than control whereas feeding on lettuce leaves only, the overall performance of silkworms was comparatively reduced and larvae don't develop and finally died. Many researchers have shown that the larval and cocoon characters improve by different concentration of plant extracts $[5,11]$.

The improvement in silk productivity might be due to the useful biochemical constituents present in the lettuce leaves, better feeding and bioavailability of nutrients to the larvae through mulberry leaf. The results are in 


\section{International Journal of Zoology and Animal Biology}

agrement with the findings of Shahin, et al. [12] who also observed an increase in silk productivity when mulberry leaves were fortified with $0.10 \%$, lettuce oil. Murugesh, et al. [13] treating mulberry leaves with T. procumbens, $T$. terrestris and $P$. hysterophorus improved the silk production. Further, Sridevi, et al. [14] also found treated mulberry leaves with $W$. somnifera increased silk production in (6.68 $\mathrm{cg}$ per day) followed by T. cordifolia (6.21 cg per day) and T. arjuna (6.12 cg per day).

On the light of haemocytes study, four haemocyte types were observed in the haemolymph of B. mori larvae, namely Prs, Pls, Grs, and Oes. Similar results were found by Nakahara, et al. [15] .The number of haemocyte population might differ depending on the developmental stages and insect family [16]. Strand, et al. [17] reported, GR was the most abundant hemocyte type in Lepidoptera larvae .Also, It has been shown that $\mathrm{Gr}, \mathrm{Pl}$, and Oe play important roles in silkworm immunity [15]. Gr, $\mathrm{Pl}$, and $\mathrm{Oe}$ are participating in phagocytosis, nodule formation, and PO activity, respectively. The effect of feeding larvae on lettuce leaves as a secondary host was study on haemocytes and defense responses of $B$. mori larvae. In this study, the THC, Gr, and Pl during feeding regime significantly increased, except at treatment (T5) and (T6). Reductions in THC, Prs, PLs and GRs of insects during feeding large amount of lettuce leaves as groups (T5) and (T6) treatment are reported to due to toxic effect of some botanical compound of lettuce leaf, inhibitory effects of these compounds on endocrine glands and their secretions and immunity response of tested B. mori larvae.

Tiwari, et al. [18] reported that ecdysone controlled the production, multiplication and differentiation of haemocytes. Moreover, the reduction in (Pr) number may be due to the inhibition of their mitotic division, their diversion to other types of haemocytes or the inhibition the response of hematopoietic organs for their production [19].

\section{References}

1. Paul DC, Rao S, Deb DC (1992) Impact of dietary moisture on nutritional indices and growth of Bombyx mori and concomitant larval duration.

2. Narasimhanna MN (1988) Manual on silk of production. Central silk board Banglore, India pp: 111.
3. Adeduntan SA (2013) Nutritive effects of Leaf position of Mulberry Plant Morus alba on Silkworm Bombyx mori L. Performance. Advances in Life Sciences 3(2): 23-27.

4. Nasreen A, Cheema GM, Ashfaq M (1999) Rearing of Silkworm Bombyx mori L. On Alternate Food Plants. Pakiestane journal of biological Science 2(3): 843845.

5. Krishnaprasad NK, Sannappa B, Reshma TK, Prasad PK (2001) Effect of solanaceous leaf extracts on growth, development and cocoon traits of PM $\times$ NB4D2 silkworm (Bombyx mori L.). Bull. Indian academia, Sericulture 5: 42-47.

6. Muthunagai M (2016) Comparative study on the feeding activity of Bombyx mori with host plant Morus nigra (Mulberry) and alternative plant Ricinus Communis (Castor Plant). Journal of Agriculture and Vertebrate. Science (IOSR-JAVS) 9(12): 29-33.

7. Mou B (2005) Genetic variation of beta-carotene and lutein contents in lettuce. American Society of Horticultural Science 130: 870-876.

8. David WS (2007) Genome mapping and molecular breeding in plants. Vegetables 2-Lettuce 5: 127-140.

9. Jones J C (1962) Current concepts concerning insect hemocytes. American Zoology 2: 209-246.

10. Gad Abir (1996) Physiological studies on lepidopterous insects. Master thesis, Faculty of Agriculture, Alexandria University.

11. Cheng, L, Huang H, Chen S, Wang W, Dai F, et al. (2017) Characterization of silkworm larvae growth and properties of silk fibers after direct feeding of copper or silver nanoparticles. Materials \& Design 129: 125-134.

12. Shahin R, Gadelhak G, Mahmoud SM, El-Agamy EI, Idriss M (2013) The effects of Lettuce seed oil on some economical parameters of the mulberry silkworm Bombyx mori L. Journal of Applied Science Research 9 (4): 2702-2707.

13. Murugesh K, Mahalingam I (2005) Influence of Tribulous terrestris L. on the growth of silkworm, Bombyx mori L and its impact on economic traits. In: Progress of research in organic sericulture and Seri - 


\section{International Journal of Zoology and Animal Biology}

by products utilization, University of Madras, Vellore pp: 151-155.

14. Sridevi G, Basker RN, Devaiah MC (2003) Influence of medicinal plant extracts on cocoon parameters of silkworm, Bombyx mori L. National conference on tropical Sericulture for Global competitiveness. CSRTI. Mysore.

15. Nakahara Y, Shimura S, Ueno C, Kanamori Y, Mita K, et al. (2009) Purification and characterization of silkworm haemocytes by flow cytometry. Dev Comp Immunol 33(4): 439-448.

16. Giglio A, Battistella $\mathrm{S}$, Talarico FF, Brandmayr TZ, Giulianini PG (2008) Circulating haemocytes from larvae and adults of Carabus (Chaetocarabus) lefebvrei Dejean
(Coleoptera: Carabidae): cell types and their role in phagocytosis after in vivo artificial non-selfchallenge. Micron 39: 552-558.

17. Strand M (2008) The insect cellular immune response. Insect Science 15: 1-14.

18. Tiwari RK, Pandey JP, Kumar D (2006) Effects of some neem-based insecticides on metamorphosis, haemocytes and reproductive behavior in red cotton bug. Dysdercus koenigii Fab. (Hemiptera: Pyrrhocoridae). Entomology 31: 267-278.

19. Gopal NM (1910) Hand Book of Sericulture. Bangal Secretariat Book Depot Calcuta pp: 298. 